\title{
AS FESTAS DAS SEMENTES CRIOULAS: ESPAÇO DE CIRCULAÇÃO DE CONHECI- MENTOS E PRODUÇÃO DE MOVIMENTOS SOCIAIS ${ }^{1}$
}

\section{THE FESTIVAL OF CREOLE SEEDS: CIRCULATION SPACE OF KNOWLEDGE AND PRODUCTION OF SOCIAL MOVEMENTS}

\author{
Iara Aquino Henn² \\ Serinei Cesar Grigolo 3
}

\begin{abstract}
Resumo: Nós consideramos as festas das sementes crioulas no Sul do Brasil como conhecimentos que se constituem e circulam nos espaços sociais entre atores, construindo redes nos processos de interação, os quais se constituem em inovações sociotécnicas. O objetivo deste artigo é analisar as festas das sementes crioulas no Sul do Brasil à luz da antropologia das ciências das técnicas de Latour (2000) e Callon (1986) e a partir da categoria "espaço social" de Bourdieu (2004), como lugar de produção e consagração do capital simbólico mobilizado para criar grupos. A partir dessa discussão é possível fazer inferências sobre a relação entre sementes crioulas e inovação e observar aspectos da produção e circulação de conhecimento e da produção e legitimação de práticas dos movimentos sociais, de agricultores e guardiões das sementes crioulas. Estas práticas ganham signos a partir da invenção das sementes melhoradas, diferenciando-se assim de espécie da biodiversidade crioula.
\end{abstract}

Palavras-chave: Sementes crioulas. Festas das sementes. Inovação. Espaço social.

Abstract: We consider the festivals of creole seeds in southern Brazil as knowledge that constitute and circulate in the social spaces among actors building networks in interaction processes, which constitute socio-technical innovations. The objective of this paper is to analyze the festivals of creole seeds in southern Brazil in the light of anthropological science of techniques from Latour (2000) and Callon (1986) and from the category "social space" of Bourdieu (2004), as a place of production and consecration of symbolic capital mobilized to create groups. From this discussion, it is possible to make inferences about the relationship between creole seeds and innovation and to observe aspects of the production and circulation of knowledge and the production and legitimation of practices of social movements, farmers and guardians of creole seeds. These practices earn signs from the invention of improved seeds, thereby differentiating it from species of creole biodiversity.

Keywords: Creole seeds. Festival of seeds. Innovation. Social space.

1 Este artigo é baseado no capítulo “Endurecimento das Redes” das Festas das Sementes e as Jornadas de Agroecologia da Tese de Doutorado de Iara Aquino Henn, sob orientação da Prof ${ }^{a}$ Dra $^{a}$ Gabriela Schiavoni, defendida em 2011 no Programa de Postgrado en Antropología Social de la Universidad Nacional de Misiones - (UnaM), Faculdad de Humanidades y Ciencias Sociales, em diálogo com o projeto de qualificação para o doutorado de Serinei César Grígolo, sob a orientação da Prof ${ }^{a}$ Dr $^{a}$ Vivien Diesel, pelo Programa de Extensão Rural da Universidade Federal de Santa Maria - RS do ano de 2013, que tem como tema social as sementes crioulas. Ver Mais Henn (2011).

2 Licenciada em Pedagogia, mestre em Educação nas Ciências pela Universidade Regional do Noroeste do Estado do RS - UNIJUI e doutora em Antropologia Social pela Universidad Nacional de Misiones, Faculdad de Humanidades no Programa de postgrado en Antropologia Social. Professora colaboradora da Universidade Estadual do Oeste da Paraná - Unioeste, no Curso de Pedagogia.

3 Professor da Universidade Tecnológica Federal do Paraná, campus de Dois Vizinhos - PR e doutorando em Extensão Rural pela Universidade Federal de Santa Maria. - RS. 


\section{INTRODUÇÃO}

Situamos as festas das sementes crioulas ${ }^{4}$ como "processos sociais" no sentido que se enredam às práticas cotidianas vivenciadas pelos agricultores familiares nos diversos cultivos e na relação com um "laboratório vivo" de resgate, cuidado, multiplicação e troca de sementes crioulas, que se manifestam e se expressam coletivamente nas festas das sementes. Essas práticas e relações, nos indicam agricultores/as como construtores do laboratório de conhecimentos, que pode ser atribuído pela antropologia das ciências das técnicas de Latour (2000) e Callon (1986) como conhecimentos que se constituem e circulam nos espaços. Ao mesmo tempo, as festas também sugerem um "espaço social" de produção e consagração do capital simbólico que são mobilizados para a formação de grupos, a partir dos debates de Bourdieu (2004).

Desse modo, este artigo analisa os processos sociais vivenciados por agricultores/as familiares e coletivos nas Festas das Sementes Crioulas na região sudoeste, no centro-Sul e na região metropolitana do Paraná, bem como, no território centro serra no Rio Grande do Sul, mais especificamente no município de Ibarama. Considerando a relação de pesquisa num contexto etnográfico é que se configura a análise deste trabalho a partir da participação e observação nas festas das sementes, de construção de narrativas de vida de grupos familiares inseridos na agricultura ecológica, das entrevistas com os participantes ${ }^{5}$ das festas e com os guardiões ${ }^{6}$ das sementes.

Neste sentido a categoria de rede de Latour (2008) está relacionada neste artigo à ideia de espaço social de Bourdieu (2004), categoria a qual remete um espaço onde se constroem as visões de mundo, e o mundo, permeado de tensões, conflitos e disputas de projetos antagônicos.

\section{Para Bourdieu (2004, p.157)}

"a sociologia deve incluir uma sociologia da percepção do mundo social, isto é, uma sociologia da construção das visões de mundo, que também contribuem para a construção desse mundo. Porém, dado que nós construímos o espaço social, sabemos que esses pontos de vista são, como a própria palavra diz, visões tomadas a partir de um ponto, isto é, a partir de uma determinada posição no espaço social ."

\section{OS GUARDIÕES E OS SENTIDOS SO- CIAIS DAS SEMENTES CRIOULAS}

As festas passam a se expandir a partir do ano 2000 por diversos municípios do Sul do Brasil, demostrando poder de mobilização. Pode-se dizer que no final da década de 1990 começaram as festas em Anchieta-SC e União da Vitória-PR, seguidas por edições em Ibarama-RS em 2002, em Francisco Beltrão-PR em 2003 e assim muitas outras foram acontecendo, como em Mandirituba-PR em 2013. Tais festas mobilizam cada uma, mais de mil pessoas e são edições ordinárias anuais enredadas em temáticas que abordam contestações e proposições na perspectiva das resistências e transformações no contexto da Agricultura Familiar Campesina.

A partir das leituras de Bourdieu (2004), se analisa as festas das sementes como

4 Semente Crioula denota muitos sentidos em disputa. A mais radical das definições demonstra que é a semente desenvolvida e adaptada pelos agricultores locais, circunscrito às comunidades rurais. Portanto são sementes do agricultor, sementes livres no sentido que eles/elas as detêm. Está sempre atrelada ao conhecimento tradicional. Todas as outras sementes que sofrem a interferência de pesquisadores são consideradas melhoradas. Esta definição pode ser acrescida e ou diferenciada pelo realce, como base de gens, qualificada como espécie da biodiversidade crioula.

5 Mediadores/as, lideranças das organizações sociais populares e governamentais.

6 Guardiões de sementes crioulas é uma categoria empírica percebida na maioria das festas das sementes para designar o agente que se torna referência pelo resgate e/ou manutenção, multiplicação e troca de sementes crioulas. Sua ação está relacionada a enunciação da existência de um Banco Vivo de Sementes sob controle dos agricultores, em alusão e contra os bancos estéreis (congelados) mantidos e controlados pelos organismos de pesquisa.

\begin{tabular}{|l|l|l|l|l|}
\hline Agric. Fam. & Belém-PA & n. 10 & p. 39-52 & dez. 2014 \\
\hline
\end{tabular}


espaços de representação do mundo social, no qual os agentes envolvidos atribuem e constroem nas diferentes dinâmicas que envolvem estas relações com as sementes, "usos sociais" e "sentidos" que permitem enunciados na relação com a inovação, construindo princípios que contribuem para suas definições e posições ${ }^{7}$ nos espaços que permitem refletir sobre o mundo do camponês ${ }^{8}$ e sobre as inovações. Em tempos anteriores as sementes eram apenas espécies da biodiversidade crioula ou nativa porque não entravam em disputa nos espaços sociais das sementes melhoradas, portanto passam a estar em disputa posteriormente dentro de um contexto de modernização da agricultura.

Entretanto, a volta das crioulas, a preservação do patrimônio genético frequentemente relacionado a um tipo de conhecimento desenvolvido pelos povos tradicionais, "quase" perdido durante o processo de modernização da agricultura significa inovação para o agricultor familiar camponês. Neste processo de resgate é que entra em disputa os tipos de sementes, os "sentidos", os "usos sociais" delas em relação à inovação. Dito de outra forma, as sementes crioulas estão sobre uma visão relacional, como poderia ser apreendida em Bourdieu, as quais passariam a existir neste sentido, nos processos sociais, a partir do momento em que passam a existir as sementes melhoradas, diferenciando-se assim da semente nativa. Fatores estes, que contribuiriam para colocar em debate sua definição e aprimorar os sentidos das sementes crioulas e melhor explicitar a denegação da inovação ou responder qual a inovação que interessa aos agricultores familiares camponeses e, da mesma maneira, diferenciar-se daqueles que cultivam sementes transgênicas.

Ao analisar a fotografia como inovação Bourdieu (2006) salienta que a mesma foi usada primeiramente em cerimoniais e tinha a função de demarcar a posição de um grupo, de firmar unidade dos envolvidos e materia- lizar a imagem que desejavam apresentar de si mesmos. A relação que podemos fazer do uso da fotografia pelos camponeses de Béarn nos inícios de 1960, estudados por Bourdieu, que admitiam a fotografia somente para ocasiões especiais e em poses que o valorizavam, rejeitando-a em outras ocasiões com o caso destes agricultores familiares camponeses ao uso das sementes transgênicas, tem a ver com a rejeição de um tipo de inovação, conferido pela incorporação dos "sentidos" e dos "usos sociais" que se faz de forma relacional entre as sementes transgênicas e as sementes crioulas, contudo é inspirador:

Terá isso a ver com ignorância, ligada a falta de informação sobre as tecnologias modernas, ou com uma vontade de as ignorar, isto é, com uma escolha cultural genuína que deve ser entendida tendo em conta os valores próprios da sociedade camponesa? Se esta última hipótese for sustentável, não poderia a história de uma tecnologia, que contradiz estes valores naquilo que lhes é mais essencial, revelar o núcleo principal da ética camponesa? (BOURDIEU, 2006, p. 31)

As festas como espaços privilegiados das sementes crioulas, nos processos sociais, podem ser interpretadas como cerimonial de consagração de seu valor, e de prestígio aos agentes que a mobilizam, com demarcação de fronteiras entre modelos de agricultura, posições e papéis das instituições, segundo os princípios da agricultura familiar camponesa, e da construção das tensões da história das sementes transgênicas e das ameaças que representam. Assim, caminham para a unidade de grupo ou coletivos organizados ${ }^{9}$, dos quais derivam as lutas e as organizações que na visão de Latour (2000) e Callon (1986) vão fazendo a construção das redes sociotécnicas.

Mesmo com a dificuldade para uma adesão mais massiva às práticas de produção e seleção de sementes crioulas, faz-se necessário a constituição de estratégias de enfren-

7 Para Latour, os sujeitos classificam-se em humanos e não-humanos.

8 Utilizamos a categoria camponês no sentido de preservar as reflexões do autor. No campo empírico tem-se encontrado o termo Agricultura Familiar Camponesa, a qual remete às lutas pela terra para diferenciar da agricultura familiar no sentido apenas político. 
tamento e resistência, as quais um interlocutor assinalou como uma prática imbricada às construções de conhecimentos - o laboratório que existe dentro das unidades de produção e vida familiar - UPVFs ${ }^{10}$ dos agricultores/ as. Neste sentido, outros interlocutores e agricultores/as assinalaram que, saber e fazer a seleção e a reprodução das suas próprias sementes, é uma das práticas adotadas para ser agroecológico/a, sendo que alguns mais, outros menos, dependendo da diversidade de itens de cultivos e da criação de animais, além do tempo que estão inseridos na agroecologia e da disposição cultural e cognitiva (LATOUR, 1999) em fazer experimentos e análises de resultados. Como exemplo tem-se o melhoramento genético dos cruzamentos das galinhas de raças puras com outras caipiras para obtenção de aves melhoradas tanto na produção e consumo de ovos e carne. Como ilustra a ênfase do dirigente na constatação do laboratório que os próprios agricultores / as têm na sua UPVF, podemos relacionar com as proposições de Latour (1999) ao assinalar a produção e circulação de conhecimentos no mesmo espaço, sem a subordinação a princípios superiores. Esta perspectiva teórica se aproxima das estratégias adotadas por agricultores/as, no sentido alternativo de selecionar e produzir a própria semente, assim como outras técnicas, de manejos, adubação verde, rotação e consorciamentos.

Observamos que este laboratório de conhecimentos nas UPVFs depende das capacidades dos interlocutores/as em fazer o experimento - ação e a reflexão - que se propõe a partir de seu potencial cognitivo de comparar, refletir e produzir novas variáveis de conheci- mentos que os levam a fazer novas experiências até tornar-se uma prática da qual não há mais dúvida, como se refere o outro agricultor ecológico e liderança nas organizações, em relação à produção de leite à base de pasto. Todavia, assinalamos que estas capacidades foram incentivadas e construídas a partir da participação dos agricultores/as nos processos sociais organizativos e de educação, por intermédio dos mediadores/as, para tornarem-se práticas cotidianas na UPVF, ou vice versa, pois, em algumas situações específicas, iniciaram no grupo familiar e novamente são levadas aos espaços coletivos para a problematização e multiplicação. Este movimento possibilita e sustenta histórica ${ }^{11}$ e culturalmente $^{12}$ a recuperação e seleção de sementes, atualmente situadas nas práticas da agroecologia.

Buscamos na narrativa do Sr. Isac e da Sra. Vilma, agricultor/a e guardião/guardiã, compreender como organizam e mantêm um banco vivo de sementes, bem como, as dificuldades que enfrentam, além dos aprendizados que vêm acumulando. Originários do Rio Grande do Sul, ela do município de Machadinho e ele de Lagoa Vermelha, vieram para a região com um dos grupos de imigrantes para a ocupação das terras devolutas do estado. Primeiramente, os pais dele se instalaram em Verê e os pais dela em Salgado Filho; os dois grupos familiares cultivavam milho e feijão, sendo que usavam muito pouco os adubos químicos e sementes Agroceres, como se refere o agricultor às primeiras sementes híbridas. Desde que vivem nesta UPVF, por ocasião do casamento há 34 anos, suas práticas no cultivo de plantas, principalmente, incluem a prática

\footnotetext{
9 O termo crioulo no sentido relacional pode ser observado num diálogo ilustrativo na revista Cambota de 1987. Duas sementes conversam sobre si e o que necessitam para produzirem, bem como, quais agricultores/as cultivam com uma ou outra e o que isso representa. Entre os elementos que diferenciam o "uso" da crioula está a condição de ser pequeno agricultor. (ASSESOAR, 1987 b, p. 04 - 05). Desde o início esta prática se distingue de outras práticas ecológicas pelo caráter sociopolítico que imprime no processo, sempre problematizando a questão da dependência dos pacotes tecnológicos da agricultura convencional.

10 Unidade de Produção e Vida Familiar (UPVF), na qual a terra não é apenas espaço de mercantilização, mas de vida e de construções sociais/culturais multidimensionais.

11 Há muitos anos que já vêm se constituindo na região sudoeste do Paraná as formas organizativas e de educação, desde os Grupos de Base até chegar a agroecologia.

12 Saberes sobre sementes vieram também com os imigrantes na ocupação das terras na região.
}

\begin{tabular}{|c|c|c|c|c|}
\hline Agric. Fam. & Belém-PA & n. 10 & p. 39-52 & dez. 2014 \\
\hline
\end{tabular}


de resgate, seleção e multiplicação de sementes crioulas.

Como guardiões de sementes crioulas iniciaram com 35 variedades de sementes, e a partir da participação na $2^{\mathrm{a}}$ Festa das Sementes na região e na festa do município de Anchieta, em Santa Catarina, ano a ano, foram aumentando seu banco de sementes. Ao perguntarmos os fatores que os levam a desenvolver a agricultura desta forma, tivemos como resposta as aprendizagens que herdaram de seus pais e avós, bem como o gosto pelo que fazem, como afirmou o Sr. Isac nas várias vezes que tivemos em sua UPVF. Mas o incentivo e o convite de outros agricultores/as ecológicos/ as e de líderes sindicais do município foram fundamentais para esses avanços, assim como o reconhecimento por parte de mediadores/ as.

Esse grupo familiar é admirado e reconhecido pelos mediadores/as, lideranças e outros agricultores/as, conferindo prestígio no sentido de Bourdieu (1989), tanto que o Sr. Isac relatou-nos todas as visitas de estudo que já fizeram na sua unidade e os incentivos dos dirigentes do Sindicato dos Trabalhadores Rurais - STR, da Associação de Estudos, Orientação e Assistência Rural (ASSESOAR) ${ }^{13}$ e das cooperativas solidárias, entre outras. Por lá já passaram educandos/as de Escolas Familiares Rurais, os agentes comunitários de desenvolvimento e crédito (ACDCs), diretores/as de cooperativas, educandos/as de cursos técnicos em geral, como consta no livro de registro de visitas. Esses intercâmbios são estratégias que se amarram entre intituições de ensino e Organizações/Movimentos Sociais, como forma de agregar mais pessoas à agroecologia. Nesses casos, conhecer, ver e escutar significa aprender com o relato de agricultores/as, com projetos de vida já consolidados. É uma porta de entrada para "esticar" a rede e "endurecê-la" também, pois quanto mais gente aderir, mais possibilidades se têm de agregar conhecimentos, práticas e estratégias nas várias dimensões produtivas, de comercialização, de luta por políticas públicas, entre outras.
Porém, surpreendeu-nos uma inferência feita pelo Sr. Isac diante da pergunta que fizemos sobre as percepções que os outros têm de si e de suas práticas. Olhou-nos de forma incisiva e nos disse: "Me acham um louco!". Ficou latente para nós o porquê dessa percepção, já que diante da agroecologia que se faz na região, seu percurso é admirável e condizente com os princípios da sustentabilidade ecológica e sociopolítica. Ou seria louco por não aderir às inovações no sentido traduzido pelos pacotes tecnológicos das grandes corporações? Ao relatar a quantidade de sementes de culturas e as variedades que possui, entendemos sua distinção em relação aos demais sistemas de agricultura, já que suas práticas revelam um potencial de conhecimentos realizados a partir de experiências que confrontadas ao do cientista de laboratório descrito por Latour (1999), constitui-se em conhecimentos. Dito de outro modo, o Sr. Isac abriu uma das "caixas pretas" da ciência e traduziu, de modo substancial: experimentando e refletindo $\mathrm{o}$ que conforma um banco vivo de conhecimentos em sua UPVF. Pois, saber como se cultiva e em que condições as trezentas e sete (307) variedades de culturas, realizando a seleção, a manutenção, a reprodução e a multiplicação destas sementes, é realmente dar curso a um "laboratório científico".

Considerando, neste sentido, a "inversão" que fez em relação às inovações tecnológicas das sementes produzidas pelas empresas e órgãos de pesquisas, tanto no que se refere à experiência em si - ao acúmulo ao longo dos anos, recuperando variedades e cultivando em pequenas quantidades - quanto ao método que chega aos seus conhecimentos, pois além destes saberes singulares, confronta e multiplica-os nos processos sociais coletivos. Observamos este saber ao narrar, por exemplo, as formas como faz para manter as variedades de milho crioulo, sabendo dos riscos de polinização e das dificuldades para evitar os cruzamentos, mesmo que cultive com 40 dias de diferença ou mais distantes em relação ao espaço; e ao mostrar em cada "cantinho" da sua unidade, algum cultivo distinto para ver

13 Fundada em 1996 é constituída e dirigida por agricultoras e agricultores familiares. Entre outras práticas, coordena a Festa das Sementes Crioulas, itinerante pelos municípios da referida região. 
no que resulta - as experiências, como algumas plantas de groselha, fruta usada na fabricação de refrigerantes ou sucos, pouco comum na região.

Apesar da "loucura" que entende lhe caracterizar, todo o relato situou-se a partir de sua fala calma e de tom baixo, dando-nos a entender que sente orgulho pelo acúmulo dessa quantidade de sementes, já que se nomeou como único no estado, relatando conhecer apenas outro agricultor da região centro do Paraná que faz experimentos nos cruzamentos genéticos. Quanto à participação e exposição nas Festas das Sementes da região e em Santa Catarina o Sr. Isac destacou que nas festas regionais somente faz a troca de sementes, enquanto nas festas de Anchieta/SC já as comercializou e que está mapeando outros eventos para participar, constituindo um espaço que além de buscar mais variedades, pode expor seu banco de sementes.

Entre as limitações que possui está a pequena área de terra de 5.2 hectares, onde faz este trabalho de multiplicação de sementes, e cultiva alimentos para a manutenção do grupo familiar. Das variedades cultivadas, muitas são também para consumo e comercialização direta ao consumidor/a na feira livre do município, na venda de porta em porta, em casas de grupos familiares e comércios. Assinalou que sua extensão de terra é toda íngreme, fator que gera dificuldades, pois sofre com os desgastes causados pelas chuvas, principalmente em períodos em que estas são abundantes. Por isso conta com alguns "pedaços" de terra de outros quatro grupos familiares para fazer as experiências e cultivos para consumo, dentre os quais, a unidade familiar onde vivem sua mãe e o irmão.

$\mathrm{Na}$ ocasião da pesquisa de campo, o Sr. Isac afirmou ter plantado 2.800 pés de mandioca, estimando colher dois mil quilos para comercialização. Perguntamos como organiza estes espaços de cultivos para manter as variedades, já que assinalou ter 16 variedades desta cultura. Neste caso, em que não há problemas de polinização, pode plantar todos no mesmo espaço, sendo que planta três carreiras de cada variedade com a finalidade de manter a semente e no restante da terra cultiva uma variedade para consumo. Com relação ao milho, à vassoura, ao milho pipoca, às morangas e às abóboras, tenta cultivar com diferenças determinadas de tempo, ou organizar o plantio de variedades em outras unidades familiares a fim de evitar cruzamentos, pelo fato de manter sementes. Assinalou que com o feijão é difícil ocorrer a polinização porque fecunda antes da floração, mas caso ocorra algum imprevisto por fatores climáticos, isso pode modificar algumas plantas. Estes conhecimentos mais técnicos advêm da relação com técnicos das organizações sociais com os quais dialoga.

Já sobre a cultura do arroz, o Sr. Isac afirmou não ter muita certeza, mas para evitar cruzamentos das sementes, tenta manter as variedades o mais longe possível uma da outra. Embora consiga fazer esta organização, relatou que faria melhor e em maior quantidade se tivesse mais extensão de terra, sendo que ele e a Sra. Vilma "queixaram-se" que se tivessem uma área maior e mais plana poderiam aumentar, inclusive, a produção que comercializam e melhorar a renda, embora a situação financeira familiar tenha melhorado depois que ela obteve o benefício da aposentadoria.

O casal enfrenta também dificuldades para manter todas as sementes recuperadas, pois entre as variedades de feijões que possuía, perdeu oito delas por causa de uma estiagem e deste período em diante recuperou apenas duas, sendo que possui 78 variedades desta cultura. Apesar da resistência das sementes crioulas, há também perdas na produção dependendo do grau das intempéries naturais. Contudo, o que se observa é que estas resistem mais do que as outras pela rusticidade que possuem e as adaptações às condições de cada região desenvolvidas ao longo dos anos. Por isso, o agricultor planta determinada variedade e reserva um pouco de sementes no banco, o que chama de arquivo. Com a colheita, renova totalmente o banco, se desfazendo daquelas que foram guardadas no ano anterior, pois esta é a característica de um banco vivo - o fato de se renovar e manter as variedades em cultivos, sendo que adotou esta prática para não perder totalmente a va-

\begin{tabular}{|l|l|l|l|l|}
\hline Agric. Fam. & Belém-PA & n. 10 & p. 39-52 & dez. 2014 \\
\hline
\end{tabular}


riedade, como aconteceu com os feijões.

Embora o cultivo tenha suas limitações, o armazenamento é um fator ainda mais complexo, pois os ambientes úmidos e pouco arejados, propensos a criar fungos, carunchos e traças, são uma dificuldade para a manutenção das sementes. O Sr. Isac possui uma peça junto à garagem, com cerca de dois metros quadrados, com prateleiras sobre as quais organiza potes plásticos e litros descartáveis de refrigerantes, onde guarda as sementes de grãos. Já para as ramas de mandioca o procedimento é mais simples, guarda-se em feixes amarradas e identificadas, assim como as sementes de tubérculos, a exemplo da batata-doce, alho e cebola, são separadas e nominadas para que não se misturem. Entre os tubérculos, possui 37 variedades, exceto alho e cebola. Em função da mudança de moradia, pois construiu outra casa com recursos de fundo perdido por intermédio do STR, planeja reformar a casa antiga para melhorar o local de armazenamento das sementes. O Sr. Isac afirmou sentir-se valorizado e reconhecido no seu trabalho, pois requer distribuir no seu tempo uma fração diária para manter viva esta prática, sendo que o grupo familiar se organiza entre a produção de sementes e os cultivos de alimentos para consumo e comercialização na feira livre e de porta em porta.

Todos os agricultores/as ecológicos/ as têm seu banco vivo de sementes na UPVF na relação com as festas, nas quais renovam, ampliam, multiplicam e partilham sementes como uma "política de valor", que implica em estratégias a serem ampliadas com a incorporação de políticas públicas, por meio de pesquisas e recursos financeiros, para atingir um número maior de agricultores/as. Ao contrapor estas estratégias que aparecem na narrativa, a exemplo do Sr. Isac, com a experiência dos agricultores/as familiares em geral, a tensão principal reside no fato de muitos destes tornarem-se monocultores/as de grãos ou produtores/as de leite, que além de não reproduzirem as sementes, sequer cultivam determinadas variedades para consumo próprio.

\section{AS FESTAS, ESPAÇOS DE PARTILHA}

No sentido atribuível pela antropologia das ciências das técnicas de Latour (2000) abre-se a compreensão das redes traçadas por ações, tensões e avanços nos diferentes contextos etnográficos, enredados à proposição de projetos de desenvolvimento multidimensional de agricultura ecológica, de lutas pela terra e da educação do campo como fios condutores para compreender as diferentes dimensões que as festas tomam. Contesta-se a política das transnacionais em relação aos monopólios das sementes, da produção, do trabalho, da integração e da regulação do mercado sobre as demais dimensões. Propõe-se uma agricultura com base ecológica e em alguns contextos etnográficos relacionados a projetos de vida multidimensionais, em outros mais ligados a lutas sociais como a luta pela terra, educação e juventude entre outras. Ambas "enredadas" em processos sociais.

As Festas das Sementes nas regiões são expressões dos processos de resgate, seleção, e reprodução de sementes crioulas. Participam agricultores/as dos diversos municípios da região. Historicamente originárias das práticas da agricultura alternativa, o movimento central é trazer e levar sementes e o comprometimento de reproduzi-las para as próximas edições do evento. $\mathrm{O}$ foco principal é a partilha das sementes, constituindo-se num banco vivo. Isto caracteriza um movimento de conhecimento, numa dinâmica de troca e de partilha.

Um exemplo destas edições é a V Festa das Sementes realizada no município de Ampére - PR no ano de 2008. A festa retrata, recria e propõe, não isenta de tensões, a agricultura que na região vem sendo construída e nomeada como alternativa, sustentável, orgânica e ecológica. $\mathrm{Na}$ abertura da festa, os depoimentos de agricultores/as que participaram de todas as edições do evento servem para memorar esse processo por meio da dinâmica do resgate das sementes, mediados pela entrega simbólica a outros agricultores/as, chamados à mesa para recebê-las; estes por sua vez, são representantes de grupos inseridos em algum processo organizativo. Segue abaixo fragmen- 
to da fala de um agricultor na abertura da festa, que simbolicamente representa a troca e a multiplicação das sementes.

“-E eu gostaria de chamar a Olívia Basso para receber essa muda como compromisso de na próxima festa das sementes, plantar ela e trazer para oferecer para outras pessoas. E também gostaria de chamar, não sei se está presente aqui, o Ivo de Santo Antônio, que também tinha me pedido e já tinha comido desta mandioca e também não tem muda, eu gostaria que ele estivesse presente aqui para receber, também se não tiver ele, algum conhecido dele pode entregar para ele essa muda de mandioca" (agricultor ecológico e feirante do município de Ampére. Arquivo de áudio).

O viés político da festa em Ampére - PR centra-se na conferência e no debate realizado com o auxílio de um pesquisador da temática sobre sementes transgênicas e os mecanismos de construção das sementes geneticamente transformadas e suas consequências, tanto do ponto de vista ecológico, quanto sociopolítico. Neste sentido, tanto a conferência, quanto as oficinas do Encontro Regional de Agroecologia, assumem este caráter sociotécnico, ao mesmo tempo em que se trabalham as questões técnicas, estas não são descoladas das análises sociais implicadas na construção e socialização de conhecimentos postos em debate (inclusive na análise da constituição das pesquisas, resultados e métodos) para apropriação dentro da rede da agroecologia (LATOUR, 1994). Poderíamos assinalar que o caráter político que os interlocutores/as se referem para caracterizar os processos, situa-se no movimento de apropriação destes conhecimentos, mas para além disso, entram em destaque as práticas que daí se geram, seja o que vai ser feito com eles, as ações que se desdobram nas unidades familiares (DE CERTEAU, 1985), sejam ações iniciais, a exemplo do jovem estudante que ao iniciar o Pós-Médio e Técnico em Agroecologia, imediatamente deixou de plantar fumo, e seu colega, que se posicionou contra o cultivo dos transgênicos na UPVF de seu pai, ou em ações mais profundas de transição da UPVF e o início com outras estratégias de produção, como as agroflorestas.

O foco central da festa é a partilha, que nesta edição acontece, sequencialmente, a partilha das sementes e a do alimento. Motivados pelo encaminhamento de um mediador, abrem-se os cordões que estavam protegendo a mesa organizada, localizada ao lado esquerdo do palco e do lado direito do público que estava sentado. Encontravam-se à disposição "saquinhos", nos quais cada um colocava as sementes, de livre escolha, tendo presente que estão à disposição em quantidades necessárias somente para sua reprodução e para que todos possam levar, sendo que as edições da festa da região não se comercializam sementes, aos moldes dos circuitos que acontecem na festa em Anchieta, em Santa Catarina. Em Ibarama - RS as sementes crioulas também são comercializadas em pequenas amostras por valores simbólicos, o que não deixa de ser uma espécie de partilha.

$\mathrm{Na}$ hora em que foi encaminhada a partilha, também foi lembrado que o compromisso é levar, reproduzir e multiplicar, isto é, trazer na próxima edição da festa, nos anos seguintes, variedades de alguma cultura. $\mathrm{O}$ público com participação equivalente entre homens e mulheres em idade adulta, algumas crianças, jovens e idosos circulam calmamente em volta desta mesa, recolhendo as sementes que querem levar consigo. Em torno de trinta minutos depois as mesas estão vazias e tanto crianças quanto adultos carregam nas mãos pacotes de sementes, tidas não apenas como grãos, mas raízes, galhos, animais, tubérculos e mudas. E não apenas de alimentos, mas de plantas medicinais e de adubação verde. Como foi dito, "Vindas de centenas de lugares, nas mãos de gente de todas as idades, lá estavam nada menos que 300 espécies de grãos, hortaliças, mudas de flores e plantas medicinais, raízes, tubérculos, frutas, ovos e animais" (ASSESOAR, 2010, p. 27).

$\mathrm{O}$ Sr. Isac assinalou que vai às festas para demonstrar a variedade de sementes que seleciona e reproduz e levar algumas para a partilha, mas sempre tenta recuperar algumas destas que perdeu em anos anteriores. Isso pode ser compreendido como um processo que evolui para a formação de um grupo entre aqueles que possuem "habitus" semelhantes e que por ocuparem posições próximas no

\begin{tabular}{|c|c|c|c|c|}
\hline Agric. Fam. & Belém-PA & n. 10 & p. 39-52 & dez. 2014 \\
\hline
\end{tabular}


espaço social tendem a desenvolver uma prática semelhante (BOURDIEU, 2004).

Da mesa de sementes, já praticamente vazia, os participantes se encaminham para as mesas que estão dispostas ao fundo do ginásio, cheias de pratos com alimentos trazidos por eles mesmos. Porém, antes do ato de partilhar, ou seja, antes de servirem-se, todos assistem em pé a uma dramatização feita por mediadores/as, vestidos e pintados de forma a representar e socializar uma reflexão sobre a distribuição do alimento no país. Este é um momento em que o foco central da festa, a partilha, é tematizada na sua questão principal: a relação da autonomia em manter em circulação as variedades de sementes crioulas em diversidade; a capacidade de fazer o melhoramento genético das aves; contextualizados pelas aspirações dos movimentos sociais e organizativos sobre a produção, soberania e segurança alimentar.

\section{A PRODUÇÃO E CIRCULAÇÃO DE CO- NHECIMENTOS E A CONSTRUÇÃO DE MOVIMENTOS A PARTIR DAS FESTAS DAS SEMENTES}

As Festas são imprescindíveis para manterem vivas as lutas no Campo como caracterizam alguns dos interlocutores participantes das edições, pois estas reúnem ao mesmo tempo mística, crítica, contestação e proposição, advindas da combinação das lutas cotidianas traduzidas na celebração. Celebrar é aqui entendido como ato de festejar, de atribuir importância, destacar o cotidiano dos grupos, tendo como foco central a partilha das sementes e dos conhecimentos, num mesmo espaço, em que cada agricultor/a leva de casa e para casa. A pedra angular (TURNER, 2005) deste contexto etnográfico é a circulação dos saberes que dão movimento a um processo de busca e de devolução de experiências, mediadas pelas simbologias ${ }^{14}$ das sementes, dos alimentos, das bandeiras como a possibilidade de partilha entre as experiências singulares (no grupo familiar) e coletivas (espaços festi- vos, organizativos e de estudo).

A partir das Festas com participação massiva vimos acrescentar à categoria da agroecologia elementos que se inter-relacionam aos outros processos ancorados no mesmo porto: o da transformação dos espaços dos interlocutores/as (UPVF) e da dinâmica dos movimentos e organizações sociais. Características mencionadas por interlocutores durante as entrevistas à experiência singular de fazer agroecologia, se acrescenta e se leva elementos das experiências coletivas e vice-versa. Esse movimento enfatiza as práticas cotidianas mediadas pelos conhecimentos sociotécnicos que na festa são "endurecidos".

O referido "endurecimento" nos remete a Latour (1999) na perspectiva da análise sociotécnica dos fatos que contribuem para a composição da rede da agroecologia, nesse caso, as festas fazem parte desta tessitura. Considerando então que fatos (práticas, estratégias, ações, conhecimentos, pesquisas, entre outros elementos) sempre que fazem poucos deslocamentos, são "moles" e fracos e nessa situação a extensão da rede também é pequena, o endurecimento de um fato, requer um trabalho longo e custoso na busca de recursos que lhe servirão de lastro para reafirmá-lo, no caso da agroecologia no contraste com outros estilos de agricultura.

É preciso então, fazer os fatos novos entrarem em debate, em contradição, em estudo com os que já existem e, por outro lado, fazer com que mais atores humanos e não-humanos componham estes fatos, enredando e tornando-os indispensáveis. Nesse sentido, as festas são processos coletivos e estratégias que contribuem para o endurecimento da rede da agroecologia.

Podemos reafirmar que a agroecologia se sustenta também na dimensão coletiva dos processos, sendo que o sentido metodológico das edições das festas é para constituir um espaço para contrastar, reformular e acrescentar (LATOUR, 1999) conhecimentos na rede sociotécnica, num movimento de reformulações daquilo que se faz nas UPVFs.

14 O simbólico, para Turner (2005), contribui para a compreensão, a conceituação de símbolos, definidos substancialmente como objetos, atividades, relações, eventos, gestos e unidades especiais. O conceito de símbolo multivocal também nos remete a perceber a festa como geradoras de significados distintos onde se situam princípios e valores desta organização social engendrada na agroecologia da região. (TURNER, 2005, p. 49 - 60) 
A continuidade das edições das festas, seguidas uma pela outra, anualmente, e a adesão em outros âmbitos municipais, regionais ou estaduais, são a mobilidade em prol das ampliações, reconstruções e consolidações destes conjuntos de conhecimentos sociotécnicos que vêm sendo disponibilizados entre os atores e demonstram essa tessitura da rede (LATOUR, 2008).

Em outras palavras, o "endurecimento" dos conhecimentos sociotécnicos depende da circulação de agricultores/as, lideranças e guardiões nos vários espaços. Nesta perspectiva, interessa analisar que os processos organizativos e de estudo, assim como os festivos, foram apreendidos e situam-se nas lutas sociais, tendo também entre os propósitos reafirmar princípios, valores, posições e práticas que os distinguem e se opõem à agricultura convencional.

Com base nestas nuances, captadas a partir das e nas narrativas, como no relato de um agricultor ${ }^{15}$, participante das festas, na expressão "Numa festa das sementes, tu se acha com o teu povo, fala a mesma língua, então eu me sinto em casa [...]", compreendemos que para o agricultor/a festa das sementes é a identificação com outros que também têm projetos de vida na mesma perspectiva, enquanto para um mediador, além disso, é também espaço de fortalecimento das práticas. Nesse sentido, a estratégia é a articulação entre movimentos sociais singulares e coletivos como reunião de ideais, valores, posturas e a reafirmação destes no "endurecimento" da rede (LATOUR, 1999) que vimos acrescentar nas posições dos agricultores/as.

$\mathrm{Na}$ agroecologia são resgatados e reconstruídos outros princípios, regras, relações, que priorizam a diversidade ${ }^{16}$ - a biodiversidade, em conflito com as ideologias e práticas do modelo gerado a partir da modernização conservadora e das empresas exploradoras de recursos naturais, no patenteamento e exploração de espécies, que deixam de ser de domínio público para submeterem-se ao controles e interesses privados, a partir dos quais são gerados para embates e enfrentamentos.

As festas nos diferentes contextos da pesquisa também se situam no caráter simbólico que imprimem nos processos sociais aos quais estão enredados. Bourdieu dá mais ênfase às condições materiais e institucionais de criação e transformação dos mecanismos de produção simbólica.

Sendo assim, as festas, exemplo de lugar de enunciação dos "princípios de divisão e visão do mundo social" (BOURDIEU, 2004b, p. 33) onde este mundo é expresso entre aqueles que se utilizam das sementes crioulas, símbolo de vida e de biodiversidade, enquanto as sementes transgênicas são banidas e identificadas como símbolo de morte, opressão, contra o mundo natural/ecológico e social. Opera-se uma exclusão das sementes transgênicas e junto com elas seus produtores, ao mesmo tempo em que associam, formam grupos em torno da agroecologia.

Miceli nos apresenta em a "força do sentido", como o poder simbólico constrói a representação do mundo social (MICELI, 2013, p. 12). A Festa das Sementes enuncia uma definição de mundo que é construída de forma relacional e contra a visão hegemônica, ou seja, o mundo do agronegócio, cuja lógica economicista predomina sobre as demais dimensões, ou melhor, sobre os demais capitais como o cultural e o social. Em tais espaços sociais se verifica a predominância de capitais específicos, resultante de lutas anteriores entre grupos que se comportam como classe em formação, situados em determinada estrutura social que produz e ao mesmo tempo é reproduzida ou ajustada nas estruturas mentais.

15 Agricultor ecológico, reassentado do MAB e membro do conselho de certificação participativa da Rede Eco Vida.

16 Tomamos o conceito de biodiversidade a partir de Escobar (1997 b). O referido autor aborda biodiversidade a partir dos Movimentos Sociais, entendendo estes como aqueles que, mesmo reconhecendo o discurso da biodiversidade como dominante na sociedade globalizada, o contrapõe à construção de estratégias políticas na defesa do território cultural e identidades ligadas a determinados lugares históricos territoriais, mediados por considerações políticas e ecológicas.

\begin{tabular}{|c|c|c|c|c|}
\hline Agric. Fam. & Belém-PA & n. 10 & p. 39-52 & dez. 2014 \\
\hline
\end{tabular}


As festas podem funcionar como um campo de produção ideológico ou contra ideológico necessários à luta política dos movimentos sociais, à medida que elas revelam a posição social dos agricultores familiares camponeses em relação ao agronegócio, enunciando princípios e visão de mundo que desejam disputar como válidos para toda a sociedade e, desta forma, desnaturalizar a aceitação da posição social que ocupam, transformando-se em força de mobilização. No polo oposto, atuam com o mesmo procedimento de classificação social e imposição de visões de mundo e princípios do capital econômico.

As festas das sementes como "espaço social de relações objetivas" (BOURDIEU, 1989, p. 64) entre os agentes que se fazem presentes em suas edições, sejam do sindicalismo, organizações da igreja, do cooperativismo, das ONGs, da pesquisa, entre outros, tem como primeira intenção a ampliação do movimento entre os movimentos e as organizações. A forma como as festas são organizadas incluem um amplo conjunto de parcerias, apoiadores, mesmo que ainda não possuam trabalhos específicos em sementes, estes aderem em razão de representarem grupos sociais que se desejam unificar. Em segundo lugar é produzir nestas "relações informais de poder" (BOURDIEU, 1989, p. 64) relações formais com o campo político e com o campo burocrático, com o propósito de influenciar nas políticas públicas. Este processo confere legitimidade e prestígio ("intenção objetiva" não declarada) a quem de fato coordena as festas, aos que guardam as sementes e a quem assume a representação e a demanda junto ao campo político, como uma espécie de "produção e circulação de bens simbólicos [...] em diferentes instâncias definidas pela função que cumprem na divisão do trabalho de produção, de reprodução e de difusão de bens simbólicos"(BOURDIEU, 2013, p.105), que neste caso está relacionada às sementes crioulas.

As festas das sementes são, por vezes, espaços de coleta e de organização do acervo de sementes que se levam para exposição, encantamento e troca. Nas festas onde a Comissão Pastoral da Terra - CPT tem maior in- fluência, a alimentação também é partilhada e trocada, conferindo valor entrelaçado com as sementes. Alimento e semente, nestes casos, estão diretamente relacionados à questão da terra e da justiça social. Edições como essas, exigem dos participantes uma interação, e uma postura que tende a se introjetar como "habitus", e "serve para referir o funcionamento sistemático do corpo socializado" (BOURDIEU, 1989, p. 62).

Nota-se na estética das festas das sementes crioulas um modo de percepção do mundo social e natural. Seus cartazes contêm sementes com asas, dando margem para interpretá-las como sementes livres dos monopólios e dos agroquímicos; sementes como dom da terra, sementes como gênese da vida, que tentam recuperar ou criar sentidos do campo religioso que se somam aos capitais culturais dos agricultores. Acolhimento alegre e celebrativo, exaltação à vida, ao diálogo, mística, arrumação do local com plantas, alimentos e sementes criam um ambiente que animam os participantes a viverem uma mudança de práticas que reforçam o capital simbólico em detrimento do capital econômico.

Os embates em torno das sementes crioulas revelam a gênese de um polo que tem do lado oposto, a produção profissional de sementes melhoradas - sementes como mercadoria. Ambos os polos têm autonomia relativa de organização ideológica, contudo são dependentes de um órgão do Estado, que lhes retira a autonomia normativa sobre as sementes. Por esta razão os embates também ocorrem entre o campo político e o burocrático. Na festa de Ibarama, coordenada pela Emater enuncia-se o desejo que as sementes crioulas passem a concorrer com as sementes melhoradas, aumentando o uso comercial das sementes crioulas. Pode-se perceber o conflito que se instaura para concorrer pelo título de "boa semente". Nesta disputa sociopolítica, capitais são enunciados e revelam "princípios específicos de percepção e de apreciação do mundo natural e social e das representações [...]" (BOURDIEU, 1989, p. 297).

Contudo os participantes durante as edições das festas são estimulados a incorporar como atitude, a troca das sementes e a 
partilha dos alimentos, envolvendo-se na dinâmica de encantamento, formulando uma expressão que tende a durar na prática da reprodução das sementes levadas para casa, dotando-as de "sentido" e "valor" (BOURDIEU, 2013). A troca de conhecimentos e de produto, nestes casos alimentos e sementes como bens culturais, produzem grupos, estes por sua vez, passam a representar o movimento das sementes crioulas, o que pode sugerir a gênese de um campo de conflitos, tensões e proposições.

\section{CONSIDERAÇÕES FINAIS}

Por fim, a crença no valor e o poder de estabelecer valor às sementes crioulas parecem dar sentido às festas das sementes. Estas, portanto, são instrumentos de lutas, associadas à defesa da vida, à defesa como patrimônio da humanidade; como sinônimo de liberdade aos mercados, como direito a alimentos saudáveis, ou simplesmente como lembranças dos modos de vida do passado.

Como se fosse arte, o valor não se dá só no momento de criação do produto, mas em nosso caso, as sementes crioulas conferem legitimidade no lugar de exposição aos pares, no lugar de ampliação do uso, que é o lugar de consagração do valor e aceitação dos princípios. Criar um lugar de construção e de enunciação do valor simbólico para as sementes crioulas, que se deseja ver reconhecido é uma forma de mobilização pelo poder de atribuir valor. Biodiversidade, valor à vida, alimento, autonomia, denegação ao econômico, são cifras que se oferecem como força de mobilização para a construção do movimento (BOURDIEU, 2004). É também um espaço em que se afirma a unidade de ação por princípios de divisão e visão de mundo. Os sentidos atribuídos às sementes e à inovação são associados à posição que os agentes ocupam no espaço social.

As sementes, a partir da análise em Bourdieu, não podem ser consideradas em si mesmas, como cor, gosto, produção, homogeneidade, padrão, ou diversidade, ou seja, suas qualidades técnicas. Constituem-se num sentido social, pois passam a ser uma categoria política aliada à posição no espaço social que ocupam os guardiões, os agricultores, os participantes das festas.

Sendo assim, as festas das sementes possibilitam assentar, sustentar e "endurecer" a rede sociotécnica em construção no contexto da agroecologia e das lutas sociais. Classificados por este viés, vimos, ouvimos e sentimos nas vivências das Festas das Sementes um espaço em que se revitaliza, junta forças e se expõem à sociedade este sistema em construção, que envolve além das relações no campo, os atores da cidade não apenas como consumidores/as que poderiam se tornar e demandar uma produção ecológica, mas para somar com outras bandeiras de luta que podem compor um projeto social distinto.

Nestas festas identificamos as práticas (DE CERTEAU, 2007) que evidenciam além das formas distintas de fazer agroecologia, a recusa ao que é dado como pronto e acabado, a exemplo dos pacotes tecnológicos, configurando o caráter polêmico que fala o autor, ao reunir condições para intervenção dentro de um contexto de "jogos de força". Assim, as estratégias são pensadas dentro da rede, amarradas nestes eventos festivos pelos fios das práticas singulares que dão coesão aos coletivos políticos socializados, redimensionados e revitalizados no conjunto das festividades por um lado e por outro, pelas formas de contestação política que inferem as Festas das Sementes. Mostrar à sociedade e chamá-la para o compromisso com as bandeiras de luta, num mesmo evento que coloca em destaque ciência e tecnologia para que não evaporem os conhecimentos sócio técnicos da rede (LATOUR, 1999) e materiais produzidos nas mediações e unidades familiares, "enredadas" às lutas sociais, para que isso tenha espaço na disputa que se trava na sociedade.

\begin{tabular}{|c|c|c|c|c|}
\hline Agric. Fam. & Belém-PA & n. 10 & p. 39-52 & dez. 2014 \\
\hline
\end{tabular}




\section{REFERÊNCIAS}

ASSESOAR - Associação de Estudos, Orientação e Assistência Rural. Quem controla a semente controla o mundo: um olhar a partir das festas das sementes: A estratégia adotada pelas organizações de agricultores familiares do sudoeste do Paraná em relação às sementes. Francisco Beltrão: Assesoar, 2010. 34 p.

\section{ASSESOAR; FACIBEL. Projeto Vida na}

Roça: da produção agropecuária ao plano da educação participativa. Francisco Beltrão: Assesoar, 1997b. v. 2.

BOURDIEU, Pierre. A economia das trocas simbólicas. São Paulo: Perspectiva, 2013. (Coleção Estudos).

BOURDIEU, Pierre. Espaço social e poder simbólico In Coisas ditas. São Paulo: Brasiliense, 2004.

BOURDIEU, Pierre. O Camponês e a Fotografia. Revista de sociologia e política, v. 26, n. 26, p. 31-39, 2006.

BOURDIEU, Pierre. O poder simbólico. Lisboa: DIFEL, 1989. (Coleção Memória e Sociedade).

BOURDIEU, Pierre. Usos sociais da ciência. Unesp, 2004 b.

CALLON, Michel. Éléments pour une sociologie de la traduction: la domestication des coquilles Saint-Jacques et des marins-pêcheurs dans la baie de St. Brieuc. L'Année Sociologique. Paris, v. 36, p. 169-208, 1986. Número spécial.

DE CERTEAU, Michel de. Teoria e método no estudo das práticas cotidianas. In: SZMRECSANYI, Maria Irene de Q. F. (Org.). Cotidiano, cultura popular e planejamento urbano. São Paulo, FAU-USP, 1985. p. 3-19.
ESCOBAR, Arturo. El desarrollo sostenible: diálogo de discursos. In: El final del salvaje: Naturaleza, cultura y política en la antropología contemporánea. Santafé de Bogotá: CERBEC-ICAN, 1999. p. 75-97. (Colección Antropología en la modernidad, n. 3).

ESCOBAR, Arturo. Whose Knowledge, Whose Nature? Biodiversity Conservation and Social Movements Political Ecology. Journal of Political Ecology. v. 05, p. 53-82, 1997 b. Disponível em: <http:/ / www.cddc.vt.edu/ ept/eprints/3escobar.pdf>. Acesso em: 06 jan. 2009.

HENN, Iara Aquino, Atores de Conhecimento e Intervenção: a Construção Social da Agricultura Ecológica. 2011. 518 f. Tese (Doutorado em Antropología Social) - Faculdad de Humanidades y Ciencias Sociales, Universidad Nacional de Misiones - (UnaM), Possadas, Argentina, 2011.

LATOUR, Bruno. Ciência em ação: como seguir cientistas e engenheiros sociedade afora. São Paulo: UNESP, 2000. 438 p.

LATOUR, Bruno. Como redividir a grande divisão. Mosaico - Revista de Ciências Sociais, Vitória - ES, v. 2, n. 1, p. 168-199, 1999.

LATOUR, Bruno. Jamais fomos modernos: ensaio de antropologia simétrica. Tradução Carlos Irineu da Costa. Rio de Janeiro: Editora 34, 1994. (Coleção TRANS).

\section{LATOUR, Bruno. Reensamblar lo Social:} una introducción a la teoria del Actor-Red, Buenos Aires: Manantial, 2008. 392 p.

MICELI, Sergio. Introdução: a força do sentido. In: BOURDIEU, Pierre. A economia das trocas simbólicas. São Paulo: Perspectiva, 2013. (Coleção Estudos).

TURNER, Victor. Floresta de símbolos: aspectos do ritual Ndembu. Tradução Paulo Gabriel Hilu da Rocha Pinto. Niterói, RJ: Universidade Federal Fluminense, 2005. 488 p. (Coleção Antropologia e Ciência Política, 35). 
